\title{
The Educational Philosophy and Development Direction of School of Foreign Studies in Engineering Colleges in China: A Case Study of North China University of Water Resources and Electric Power (NCWU)
}

\author{
Wei Xinqiang \\ School of Foreign Studies, North China University of Water Resources and Electric Power \\ 36. Beihuan Road, Zhengzhou, China \\ Tel: 86-371-6931-0181Ｅ-mail: weixinqiang@ncwu.edu.cn
}

Received: March 26, 2012 Accepted: April 1, 2012 Online Published: May 21, 2012

doi:10.5539/hes.v2n2p168

URL: http://dx.doi.org/10.5539/hes.v2n2p168

This paper is the research result of Talents Cultivation Model Study of the Major of Chinese teaching as Foreign Language in the Multi-language Context, supported by the Teaching Reform Projects of North China University of Water Resources and Electric Power in 2011 and Education Department of Henan Province in 2012.

\begin{abstract}
This paper gives a brief analysis on the educational advantages and objects of NCWU. It believes that the educational philosophy and development direction of foreign school in engineering colleges must be set up on the basis of need of China and talents need, moreover, the development of the School of Foreign Studies must be analyzed by integrating into the whole development of NCWU. This paper put forwards the educational philosophy of "Drawing on Advantages, Avoiding Disadvantages, and Gearing Education to Society" and the Development Direction of "Rooted in Foreign Language and Characterised by Engineering and Business". It analyzes the problem of school of foreign studies in NCWU in Specialty Construction, teaching team and Construction of Discipline and puts forwards some solutions.
\end{abstract}

Keywords: Educational philosophy, School of foreign studies, Engineering colleges in China, North China University of Water Resources and Electric Power (NCWU)

\section{Introduction}

In recent years, North China University of Water Resources and Electric Power (NCWU) has upheld the banner of scientific development and carried out the strategy of scientific development, which has won the harmonious development of the size, structure, quality and efficiency of the university. Teachers' development has also boosted the overall strength and the social impact of NCWU. Now the university is turning into a high-level teaching and research university with its distinct characteristics. Under the correct leadership and strong support of the university, the School of Foreign Studies, adhering to the tradition of NCWU, brings together the educational resources, and continues to explore and improve educational methods and philosophy in practice. The school also adjusts the direction of its development timely to the development of NCWU and to the needs of the society. Besides, it promotes the teaching reform, improves the teaching quality and cultivates numerous talents to enhance the ability of serving for NCWU, Henan, and the society.

\section{Educational Philosophy and Development Direction}

In recent years, with the continuous expansion of the university scale, almost the majority of the junior colleges and universities have set up the school of foreign studies. In addition, there are many private institutions setting up the school of foreign studies as the characteristics of their education. This situation is conducive to cultivate the talents of foreign languages. Obviously, it also shows that the internal competition among the schools of foreign studies has become increasingly violent. What's more, after entering the 21st century, the disciplines related to foreign studies, such as International Trade, Foreign Law, International Relations, International News have evolved into the model of "major plus foreign language", which not only makes a great impact on the traditional pattern and training model of foreign language education, but also brings about a series of inevitable questions to every school of foreign 
studies: In order to have a better development with distinct characteristics, what educational philosophy should school of foreign studies adhere to? What abilities should it train the students? What development path should it take? etc.

\subsection{Foundation of Educational Philosophy and Development Direction}

The educational philosophy and development direction should be established based on our nation's demand for education and talents. The Teaching Syllabus for Foreign Language Majors of Higher Learning puts forward the clear training objectives and specifications for foreign language students in the new era: "They should have well-knit basic skills, a broad range of knowledge, a certain degree of expertise, good abilities and high quality, i.e., besides laying a solid foundation of basic skills of foreign language and mastering the foreign language expertise, they should broaden the knowledge of humanities and technology, grasp professional knowledge related to the work they take on after graduation, foster the abilities of acquiring knowledge, think independently and creatively, and improve the qualities of moral, culture, and psychology. "

The establishment of educational philosophy and development direction should be combined with the objective environment and it should be based on the correct analysis, accurate positioning and rational planning. Therefore, the development of the School of Foreign Studies must be analyzed by integrating into the whole development of NCWU. Looking back at history, the establishment and development of the School of Foreign Studies always accompanied and relied on the development of NCWU. School of Foreign Studies was formerly known as the foreign teaching and research section of the Basic Subjects Department. With the development of NCWU and due to the need of education, Foreign Language Teaching Department was set up on December 28th, 1998, and it became a secondary teaching unit. In April, 2002, it was renamed Foreign Language Department and began to recruit English majors. In 2008, another discipline, i.e., teaching Chinese as a foreign language, was added to the Department. In April, 2009, Foreign Language Department was renamed School of Foreign Studies, which marked an important stage in its development. It could be known that the development of the School of Foreign Studies benefited from that of NCWU. It also contributed to the development of NCWU in turn. In the future, the School of Foreign Studies will adapt to the changes of the times, gear education to social needs, bring forth reformation and innovation, and make continuous improvement under the guidance of NCWU and according to our nation's demand for foreign education.

\subsection{Educational Philosophy of "Drawing on Advantages, Avoiding Disadvantages, and Gearing Education to Society}

The compendium on the development of NCWU has proposed and perfected the goal of "establishing a high-level teaching and research university with its distinct characteristics". Distinct characteristics of education and talent cultivation are also the demand of the Ministry of Education for higher institutions, and it should be the goal for higher institutions. In such an environment, the development of School of Foreign Studies should be based on the characteristics of NCWU, combine with the actual situation, take advantage of various resources, foster new growth points in the development of the school, and produce foreign talents with solid foundation and obvious advantages. Thus, our students' with unique talent can outshine the students from other numerous universities and obtain employment.

In light of the distribution of provincial-level key disciplines, NCWU is a comprehensive university with distinct characteristics featuring engineering and science. It is of great importance for school of foreign studies to identify its position in the whole development of NCWU. This is also a must and the first step for us to be realistic and objective.

The strength of engineering in NCWU is powerful, which provides a wealth of resources, solid foundation and various favorable conditions for School of Foreign Studies to take a road to development with its distinct characteristics. This is our advantage and what we should rely on for future development. If we do not take advantage of the existed conditions, but try to compete with other famous foreign studies universities having dominant advantages in traditional foreign field such as linguistics and literature, even if it is not impossible to stand out, it is very difficult to success in the short term.

Therefore, "draw on advantages and avoid disadvantages, gear education to society" should be the guidance in the development of School of Foreign Studies. The needs of society and job market should be the starting point to train the talents. We can figure out our goal by making full use of the advantage of NCWU featuring engineering, integrating various resources and combining with the fact that the majority of the employers are from companies related to water resources and electric power. Thus, the welcomed inter-disciplinary talents, with sound foundation of foreign language, basic knowledge of water resources and electric power, and capable of translating documents related to international projects and negotiations, should be trained by School of Foreign Studies. Setting this goal 
needs us to have a clear picture of the situation, adapt to the needs of the market and the society, and make full use of the existed advantages. The limited time, energy and resources should be used fully to reinforce the students' foreign language foundation, and broaden students' expertise that is in favor of employment. The good employment will help School of Foreign Studies to be competitive during the period of university enrollment and employment. Ultimately, our school will stand out in numerous Schools of Foreign Studies and become the famous brand of foreign language among engineering universities.

\subsection{Development Direction of "Rooted in Foreign Language and Characterised by Engineering and Business"}

"Rooted in Foreign Language" refers to foreign language learning should be the base, the starting point and the focus of our working. "Characterised by Engineering and Business" means that based on foreign language learning, we should take advantage of the rich resources of engineering and gear our education to the needs of such fields as engineering and business. The talents we produce should have a sound foundation of foreign language and have the basic knowledge related to business. They are able to translate documents of engineering projects and can carry out business negotiations. Thus, they will be welcomed by the employers. In this way, not only can the employment rate be improved, but also can form the distinct characteristics distinguishing our school from other Schools of Foreign Studies. Our school will form a famous foreign language educational brand eventually and become the cradle of foreign language talents with knowledge related to engineering and business.

Determining such a development direction is based on the thinking of the status quo of the current foreign language education and the actual situation of our university, as well as the educational philosophy of "Drawing on Advantages, Avoiding Disadvantages, and Gearing Education to Society". It is the understanding and analysis of current situation and the prediction of development trend in the future. Nowadays, Schools of Foreign Studies are set up in almost every colleges and universities; therefore, whether the distinct characteristics can be formed by relying on advantageous resources will be the determining factor for the development of School of Foreign Studies. On the one hand, School of Foreign Studies must take the foreign language education as the foundation. If too much emphasis is put on the non-foreign language component, the school itself will lose its own independence and the meaning of existence, and it will become neither fish nor fowl. On the other hand, we must have a clear mind of the actual social need of the talents specialized in linguistics or literature. The overemphasis on linguistics or literature at the undergraduate stage will lead to deviations from social needs and such talents can neither carry out theoretical research nor have the ability of application and they will be unfit for a higher post but unwilling to take a lower one.

NCWU has a significant advantage and rich resources in the field of engineering, especially in water resources and electric power. Therefore, employers coming to NCWU mostly want students in these fields, in hope of employing talents who has great language skills and are capable of carrying out business negotiations. The development direction of "Rooted in Foreign Language and Characterised by Engineering and Business" is the guarantee of keeping pace with the times and meeting the needs of our society. It is also the assurance that School of Foreign Studies can make further development in future fierce competition in terms of oversupply of foreign language talents. Only to stick to this development direction can School of Foreign Studies keep vibrant of life in the process of economic development and education reform.

\section{Specialty Construction}

\subsection{Problems School of Foreign Studies Facing}

At present, many Schools of Foreign Studies face some problems in the system of specialty as lack of distinct characteristics. More specifically, there are the following several aspects.

Firstly, the orientation of the specialty is not clear enough. The foreign language, set up as an independent discipline in China's institutions of higher learning, is not learned to serve for a particular field or occupation. Therefore, this unclear orientation leads to a strong dependence of foreign language on other specialties or fields, and foreign language has become a tool of other specialties. Thus, the specialty of foreign language is placed in an awkward position and foreign language learners are regarded as "students without a practical specialty".

Secondly, the curriculum is monotonous. Traditionally, the courses of foreign language are often set up according to the specialty requirements of Foreign Language Literature. There are courses such as basic foreign language, reading, listening, phonetics, speaking, introduction to foreign culture, foreign literature, translation and linguistics. These courses are set to help students to gain knowledge and master certain language skills. What they have learned is not extensive enough. Even there are students hoping to learn some knowledge related to other specialties, they cannot get efficient guidance. In this sense, the monotonous curriculum objectively leads to the "students without a practical specialty".

Thirdly, the monopolistic advantage of foreign language disappears, while the new advantage has not appeared. At 
the beginning of the policies of reform and opening to the outside world, the specialty of foreign language is mainly set up in foreign studies universities, comprehensive universities or normal universities. However, in recently years, with the continuous expansion of the university scale, almost all of the colleges and universities have set up this specialty. In addition, there are many private colleges and universities setting up this specialty as their educational characteristics. On the one hand, this will be conducive to the cultivation of more foreign language talents. On the other hand, it also shows that the competition of training of foreign language talents has become increasingly violent. In addition, many disciplines related to foreign studies, such as international trade, foreign law, international relations, international news have evolved into the model of "major plus foreign language", which makes a great challenge to traditional foreign language talents with pure language skills.

\subsection{Construction Ideoglogy of "Foreign Language as the basis, Engineering and Business for Practice"}

The Education Reform of Foreign Language Majors at the College Level for the 21st Century has pointed out that "Due to the society demand for foreign language talents has shown a trend of diversification, the talents with pure language skills or basic skills cannot meet the needs of market economy. The market demand for graduates majoring in Foreign Language Literature is gradually reduced. Therefore, the foreign language education must change from the model of scholasticism to inter-disciplinary talents training.......An urgent need in foreign language teaching has emerged, i.e., to increase diplomatic, economic and trade, and financial knowledge on the basis of existing literature and linguistics." The Teaching Syllabus for Foreign language Majors of Higher Learning, which was revised in March, 2000, has put forward the clear training objectives and specifications for foreign language students in the new era: "They should have well-knit basic skills, a broad range of knowledge, a certain degree of expertise, good abilities and high quality, i.e., besides laying a solid foundation of basic skills of foreign language and mastering the foreign language expertise, they should broaden the knowledge of humanities and technology, grasp professional knowledge related to the work they take on after graduation......" The above mentioned document explicitly requested that foreign language cannot exist only as a "pure language" major, but should become a "foreign language-based discipline with other practical disciplines as its content". It should be a new filed focusing on the ability of application. That is to say, "Foreign Language Major" should change into "Foreign Language plus Major".

Based on the above guiding ideology and the idea of "Drawing on Advantages, Avoiding Disadvantages, and Gearing Education to Society" as well as the principle of "foreign language as the base, business and engineering as development direction", School of Foreign Studies of NCWU is making great effort to reform the existing training model and to develop a new training model to meet social needs so as to improve its competitiveness and form a distinctive brand with the recognition of society. Above all, it is necessary to optimize the professional training program and highlight the program features. On the one hand, the training of basic language skills should be remained and strengthened. During the undergraduate study, more emphasis should be put on the five foreign language skills, i.e., listening, speaking, reading, writing and translation to help students lay a good foundation for basic foreign language skills and master related language skills. The content that is outdated or divorced from social needs or can be left to postgraduate study should be deleted. On the other hand, the proportion of business, science and technology courses should be increased. The courses related to water resources and electric power can be integrated into the system of foreign language courses for higher graders to learn in the combined model of compulsory and elective courses. In this way, the superiority in employment can be maintained. At the same time, students' personality, avocation, and development tendencies are fully respected. Besides, we should attach importance to social practice and create opportunities to expose students to the practical application so as to increase the chances of practices in companies and enhance the effects of practicing. In this way, students will know the society as soon as possible and can make timely adjustment. This is also good for the employers to have a better understanding of our students.

\section{Construction of Teacher Team}

The construction of a high level of discipline should have an academic team with a reasonable structure of title, degree, age and academic affiliation. Therefore, a long-term and a short-term construction plan of the teacher team are needed to gather and organize existing academic resources. Effective measures should be taken to stabilize and attract the talents with both ability and integrity to contribute to the construction of teacher team. The academic leaders and an innovative academic team can be trained through constant efforts. Besides, the personnel training system should also be perfected gradually. The best conditions for the development of talents should be created through unconventional training and use of talents, especially in the aspects of project application and research, training activities, participating in high-level academic exchanges both at home and abroad, etc.

Due to the unique nature of foreign language discipline and the objective conditions faced by School of Foreign Studies of NCWU, the structure of our teacher team needs to be further improved in terms of teachers' age, gender, 
education levels, title, etc. Therefore, School of Foreign Studies has adopted the measure of "More training activities and more new talents" to accelerate the construction of teacher team.

First of all, School of Foreign Studies has improved the structure of teacher team through more training activities. It is a long-lasting process to improve and perfect the teacher team as it not only involves teachers and the school, but also relates to administrative department of the university. The most direct method to improve teachers' education levels is to attract more talents with high degree. In light of the fact that the doctoral stations and foreign language doctors are relatively few in universities, a more feasible way is to further train current teachers. The training subjects should be mainly young teachers and ways of training should be flexible. Under the favorable condition that NCWU supports teachers' development, our school encourages teachers under the age of 35 to make personal development plans to urge them to enhance their academic and research levels. What' more, some excellent young teachers are selected to go out for further studies or to carry out short-term training abroad or to invite famous teachers to hold a series of academic lectures as well as other means to strengthen our teachers' theoretical foundation and expertise. Secondly, the research capability can be further improved by integrating various resources. It is a long and arduous process to improve teachers' research capability and this needs the joint efforts of the teachers and our school. School of Foreign Studies can give preferential incentives and provide a good environment and guarantee for teachers to carry out scientific research. Some preferential treatment can also be provided for teachers who go on with the further study to get a master or doctor degree or go out for further training. Research funding can be appropriated for teachers participating domestic and international symposiums. In addition, School of Foreign Studies provides a platform to improve teachers' research capability by taking various forms of training activities, such as inviting experts to give lectures and holding academic seminars.

The construction of the research team should also take into account the construction of teacher team. Good teachers can play their roles in the discipline development. Various discipline activities can be organized to enrich their knowledge and improve their research capabilities. It must be ensured that all the relevant teachers can participate in the teaching activities so as to improve their knowledge related to corresponding discipline and their teaching levels. Academic leaders and discipline backbones should take part in undergraduate teaching and the teaching and research activities to effectively implement the idea of good teaching contributing to the development of university. Thus, it is in favor of training innovative talents. At the same time, attention should be paid to the relative independence of teaching activities and the diversity of the talents. Teachers cannot be measured by only one standard and they should be encouraged to develop themselves in diversified directions and broad space for development should be given to both research-oriented teachers and teaching-oriented teachers.

\section{Construction of Discipline}

Disciplines are the most important organizational foundation and basic elements of colleges and universities. It is a system including the research team, discipline orientation, scientific research, basic conditions and talents training. According to the issued document of discipline classification, foreign language belongs to the classification of Arts. Foreign Language Literature is the primary discipline and Foreign Linguistics and Applied Linguistics is the secondary discipline. Foreign language, as a basic discipline, featuring in its independence and humanity, has its own disciplinary connotation, research field, knowledge structure, law of development and academic standard. Its characteristics and advantage lie in the transmission and exchange of the civilization between the western and the eastern world. The western civilization respects science and it advocates people-oriented science and technology. At present, foreign language specialty is set up in many engineering and science universities. Because people have already realized theoretically that the complement and coordinated development of technology and humanities have important strategic significance to train high-quality innovative talents.

The discipline construction of School of Foreign Studies of NCWU is based on the principle that "English as the dominant discipline, develop other languages coordinately", and it features in Business and Technology.

English, as a quasi-international language, has a indisputable position in terms of practical application or employment needs. Therefore, the discipline construction of School of Foreign Studies should put English in a dominant place, which is undisputed. To further improve the training capacity of English specialty, it is necessary to optimize the curriculum of English, i.e., to make some combination, retain, strengthen and increase some parts that are helpful for students to have a good English foundation and to be familiar with professional knowledge. Besides, it is also essential to reduce or delete some content or curriculum that is inefficient or repetitive or is not suitable to learn in this new era. However, the other languages can not be ignored. With the popularity of School of Foreign Studies in colleges and universities in recent years, English has spread far and wide. On the contrary, the other languages have sprung up quickly and are sought-after in the job market. It should be noted that due to the limited demand for talents majoring in these languages, the application and demand for these talents are far less than that of 
English. Therefore, from the perspective of discipline construction, the construction of the other languages can neither be ignored nor take precedence over English. The construction of discipline should develop moderately. The other languages should develop coordinately with English, which will become one organic part of among various disciplines in School of Foreign Studies.

Business and technology are the key disciplines with distinct characteristics in School of Foreign Studies. But it must make clear that the construction of these two disciplines in School of Foreign Studies and in their own schools is different. First, the construction of these two disciplines in School of Foreign Studies is not to develop them comprehensively, but to find the bonding point of business, technology and foreign language. The point that is selected should apply extensively in various fields and receive popularity in job market. Specifically, business refers to the foreign business; mainly practice rather than theory, including business negotiations, business trade shows, etc. While technology refers to the disciplines with significant advantage such as water resources and electric power. The employers come to NCWU often need talents related to these fields, and what we should do is to cultivate inter-disciplinary talents who can gain favor with employers.

Specifically, the construction of School of Foreign Studies in NCWU should be carried out from the following several aspects. First, it is of great importance to put emphasis on the team construction of discipline. Based on strengthening the existing foreign language research team, it is necessary to attract and train talents of the other languages, business and technology. Second, more focus should put on the research orientations of related disciplines, especially the orientations with distinct characteristics, such as business English and technology English related to water resources and electric power. Without such a general development direction, the whole discipline will lose its driving force and characteristics. Even some research will lose the guidance and foundation of development. Third, more emphasis should be put on relevant research. Research projects and scientific research are the embodiment of the level of discipline construction. High-quality research is the breakthrough of the construction of discipline, so we should give full play to support and promote the role of scientific research on discipline construction, thereby improving the overall educational level and core competitiveness. Fourth, more attention should be paid to the construction of academic degrees. Academic degree construction is an important symbol of the level of discipline construction, and the two should be combined together to improve the level of discipline. At present, our school is making effort to register and construct the foreign language master degree program and striving to reach the goal of carrying out postgraduate education based on the improvement of educational quality. Postgraduate education can provide a good platform for the construction of discipline. Therefore, the development of postgraduate education can ensure that of discipline and make discipline development more promising.

\section{Conclusion}

The prosperous development of NCWU in education and research provides a good environment for the development of School of Foreign Studies. Our school will take advantage of this opportunity, deepen the reform, continue to make exploration and improvement, and perfect various aspects, which will make a great contribution to the prosperity of the university.

\section{References}

Department of Higher Education of Ministry of Education. (1998). Advice on Regualar Undergraduate Education Reform of Foreign Languages in $21^{\text {st }}$ Century. Ministry of Education of the People's Republic of China, Beijing

Dingfang Shu. (2004). Foreign Language Reform: Problems and Countermeasures. Shanghai Foreign Language Education Press. Shanghai.

English Section of Foreing Languages Majors Teaching Guide Board, (2000). The Teaching Syllabus for Foreign Language Majors of Higher Learning. Shanghai Foreign Language Teaching Press. Shanghai; Foreign Languages Teaching and Research Press. Beijing.

Gefei Wu. (2002). On English Literature Course Teaching Reform. Journal of Sichuan International Studies University. 4.

Kemp, J. et al. (1996). Designing Effective Instruction. Pren-tice Hall

Xiubai Qin \& Guhua Wu. (1999). Development of the English education in universities of science and technology by strengthening academic discipline construction, 4, 10-14. 